\title{
Clinical pharmacology of trastuzumab emtansine (T-DM1): an antibody-drug conjugate in development for the treatment of HER2-positive cancer
}

\author{
Sandhya Girish • Manish Gupta • Bei Wang • Dan Lu • Ian E. Krop • \\ Charles L. Vogel · Howard A. Burris III - Patricia M. LoRusso · Joo-Hee Yi • \\ Ola Saad · Barbara Tong · Yu-Waye Chu · Scott Holden · Amita Joshi
}

Received: 15 November 2011 / Accepted: 28 December 2011 / Published online: 20 January 2012

(C) The Author(s) 2012

\begin{abstract}
Purpose Trastuzumab emtansine (T-DM1) is an antibodydrug conjugate comprising trastuzumab and DM1, a microtubule polymerization inhibitor, covalently bound via a stable thioether linker. To characterize the pharmacokinetics (PK) of T-DM1 in patients with human epidermal growth factor receptor 2 (HER2)-positive metastatic breast cancer, data from four studies (TDM3569g, TDM4258g, TDM4374g, and TDM4688g) of single-agent T-DM1 administered at $3.6 \mathrm{mg} / \mathrm{kg}$ every 3 weeks (q3w) were assessed in aggregate.

Methods Multiple analytes-T-DM1, total trastuzumab (TT), DM1, and key metabolites-were quantified using enzyme-linked immunosorbent assays or liquid chromatography tandem mass spectrometry. PK parameters of
\end{abstract}

S. Girish $(\bowtie) \cdot$ M. Gupta $\cdot$ B. Wang $\cdot$ D. Lu $\cdot$ J.-H. Yi · O. Saad

B. Tong $\cdot$ Y.-W. Chu $\cdot$ S. Holden $\cdot$ A. Joshi

Genentech, Inc, 1 DNA Way,

South San Francisco, CA 94080, USA

e-mail: girish.sandhya@gene.com

Present Address:

M. Gupta

Bristol-Myers Squibb, Lawrenceville, NJ, USA

I. E. Krop

Dana-Farber Cancer Institute, Boston, MA, USA

C. L. Vogel

Sylvester Comprehensive Cancer Center,

Deerfield Beach, FL, USA

H. A. Burris III

Sarah Cannon Research Institute, Nashville, TN, USA

P. M. LoRusso

Karmanos Cancer Center, Detroit, MI, USA
T-DM1, TT, and DM1 exposure were calculated using standard noncompartmental approaches and correlated to efficacy (objective response rate) and safety (platelet counts, hepatic transaminase concentrations). Immunogenicity was evaluated by measuring anti-therapeutic antibodies (ATA) to T-DM1 after repeated dosing using validated bridging antibody electrochemiluminescence or enzyme-linked immunosorbent assays.

Results PK parameters for T-DM1, TT, and DM1 were consistent across studies at cycle 1 and steady state. T-DM1 PK was not affected by residual trastuzumab from prior therapy or circulating extracellular domain of HER2. No significant correlations were observed between T-DM1 exposure and efficacy, thrombocytopenia, or increased concentrations of transaminases. Across the studies, ATA formation was detected in $4.5 \%$ (13/286) of evaluable patients receiving T-DM1 q3w.

Conclusions The PK profile of single-agent T-DM1 $(3.6 \mathrm{mg} / \mathrm{kg} \mathrm{q} 3 \mathrm{w})$ is predictable, well characterized, and unaffected by circulating levels of HER2 extracellular domain or residual trastuzumab. T-DM1 exposure does not correlate with clinical responses or key adverse events.

Keywords Trastuzumab emtansine - T-DM1 .

Breast cancer $\cdot$ HER $2 \cdot$ Antibody-drug conjugate

\section{Introduction}

Human epidermal growth factor receptor 2 (HER2; also known as $E r b B 2$, neu, or $p 185^{H E R 2}$ ) is a member of the epidermal growth factor receptor family of transmembrane receptors [1]. Gene amplification and receptor overexpression of HER 2 are observed in approximately $20-25 \%$ of human breast cancers $[1,2]$. HER2 overexpression is an 
adverse prognostic factor associated with aggressive tumor growth and poor clinical outcomes in patients with breast cancer [1-3].

Trastuzumab is a humanized immunoglobulin $\mathrm{G} 1\left(\mathrm{IgG}_{1}\right)$ monoclonal antibody that targets the HER2 extracellular domain (ECD). Trastuzumab in combination with chemotherapy is the standard of care for patients with early or metastatic HER2-positive breast cancer [3-6]. DM1, a derivative of maytansine, is a highly potent microtubule polymerization inhibitor [7-9]. It competes with vinca alkaloids for binding on the beta subunit of tubulin. In studies of HER2-positive and HER2-negative cell lines, maytansine derivatives (including DM1) are 25- to 500-fold more potent than paclitaxel [10-12] and 100-4,000 times more potent than doxorubicin [10].

Trastuzumab emtansine (T-DM1) is an antibody-drug conjugate in the clinical development for the treatment of HER2-positive cancers [13-16]. Antibody-drug conjugates are designed to target the delivery of a highly potent cytotoxic agent to tumor cells [17-19], thereby creating a more favorable therapeutic window for cytotoxic agents than would be achieved by the administration of free cytotoxic agent.

T-DM1 comprises trastuzumab linked to DM1 (0-8 DM1 molecules per antibody) using the heterobifunctional reagent succinimidyl-trans-4-[maleimidylmethyl] cyclohexane-1-carboxylate, a stable thioether linker that binds primarily to antibody lysine residues [7-9]. An average of 3.5 DM1 moieties is linked to each trastuzumab molecule in T-DM1 [16].

T-DM1 binds to HER2 with an affinity similar to that of trastuzumab [10]. After internalization of the receptorT-DM1 complex, intracellular release of DM1-containing moieties from T-DM1 is thought to occur via lysosomal degradation [20], resulting in the inhibition of cell division and cell growth and eventually culminating in cell death $[16,17]$. Moreover, T-DM1 has been shown to preserve the antitumor properties of trastuzumab, including the inhibition of HER2 signaling and the flagging of HER2-overexpressing cells for antibody-dependent cellular cytotoxicity [10, 16]. Therefore, T-DM1 is believed to have multiple antitumor effects beyond its role in target-specific drug delivery.

To date, four studies have evaluated single-agent T-DM1 at its maximum tolerated dose (MTD) of $3.6 \mathrm{mg} / \mathrm{kg}$ given every 3 weeks $(\mathrm{q} 3 \mathrm{w})$ in pretreated patients with HER2positive metastatic breast cancer (MBC). The first-inhuman phase I study (TDM3569g) established the MTD and identified transient grade 4 thrombocytopenia as the dose-limiting toxicity (DLT) at $4.8 \mathrm{mg} / \mathrm{kg}$ [13]. Results from studies TDM4258g and TDM4374g, two phase II studies of T-DM1 $3.6 \mathrm{mg} / \mathrm{kg}$ q3w for patients with HER2positive MBC who had received prior HER2-directed therapies, demonstrated overall response rates of $25.9 \%$ and $34.5 \%$, respectively $[14,15]$. The durations of responses in these latter studies are not yet estimable because of the short follow-up to date. The phase II study TDM4688g evaluated the effects of single-agent T-DM1 on the duration of corrected QT (QTc) interval; the QTc results from this study have recently been reported [21].

To assess the clinical pharmacology of T-DM1, pertinent data from these four single-arm studies were consolidated. This report summarizes all of the pharmacokinetic (PK) data obtained from the completed single-arm studies of T-DM1 in patients with HER2-positive MBC.

\section{Methods}

Studies

The TDM3569g, TDM4258g, TDM4374g, and TDM4688g studies were carried out in accordance with approval by the relevant institutional review boards, and all patients provided written informed consent before participating in each study. Patients in the phase I study had previously received a trastuzumab-containing chemotherapy regimen, and patients in the phase II studies had received a trastuzumaband/or a lapatinib-containing chemotherapy regimen in the metastatic setting and had progressed on their last treatment [13-15, 21]. In all studies, patients on the $\mathrm{q} 3 \mathrm{w}$ regimen received T-DM1 as a 90-min intravenous infusion in cycle 1 and over 30-60 min in later cycles. Patients could not have received trastuzumab within 21 days of enrollment.

The primary objectives of the TDM3569g phase I doseescalation study were to assess the safety, tolerability, and 3-week-cycle PK of T-DM1 administered by intravenous infusion on both a $\mathrm{q} 3 \mathrm{w}$ and weekly dosing schedule in patients with HER2-positive MBC who had received trastuzumab previously (Table 1). The dose levels evaluated in the phase I study for the $\mathrm{q} 3 \mathrm{w}$ regimen were $0.3(n=3)$, $0.6(n=1), 1.2(n=1), 2.4(n=1), 3.6(n=15)$, and 4.8 $(n=3) \mathrm{mg} / \mathrm{kg}$.

The primary objectives of TDM4258g, a phase II study, were the assessment of the objective response rate, safety, and tolerability of T-DM1 $3.6 \mathrm{mg} / \mathrm{kg} \mathrm{q} 3 \mathrm{w}$ in patients with HER2-positive MBC who had progressed while receiving HER2-directed therapy and who had received prior chemotherapy for metastatic disease [14]. The primary objectives of TDM $4374 \mathrm{~g}$, also a phase II study, were the same, but all patients had received prior therapy with trastuzumab, lapatinib, an anthracycline, a taxane, and capecitabine [15]. Characterization of the T-DM1 PK profile after single and multiple cycles was a secondary objective in the TDM4258g and TDM4374g studies.

The primary objective of the ongoing TDM4688g study is the evaluation of the effects of T-DM1 at $3.6 \mathrm{mg} / \mathrm{kg} \mathrm{q} 3 \mathrm{w}$ (the MTD for the $\mathrm{q} 3 \mathrm{w}$ regimen) on the duration of the QTc 
Table 1 Summary of study designs and pharmacokinetic (PK) sampling schedules for four single-agent studies of trastuzumab emtansine

\begin{tabular}{|c|c|c|c|c|}
\hline Study & $\begin{array}{l}\text { No. of } \\
\text { enrolled } \\
\text { patients }\end{array}$ & $\begin{array}{l}\text { Prior therapies required } \\
\text { for eligibility }\end{array}$ & $\begin{array}{l}\text { T-DM1 doses } \\
\text { and regimens }\end{array}$ & PK sampling \\
\hline $\begin{array}{l}\text { TDM3569g, } \\
\text { phase I }\end{array}$ & q3w: $n=24$ & Trastuzumab & $\begin{array}{l}\mathrm{q} 3 \mathrm{w}: 0.3,0.6,1.2,2.4,3.6 \\
\quad \text { and } 4.8 \mathrm{mg} / \mathrm{kg}\end{array}$ & $\begin{array}{l}\text { Intensive sampling in cycle } 1 ; \\
\text { peak/trough PK sampling in } \\
\text { subsequent cycles; NCA of PK data }\end{array}$ \\
\hline $\begin{array}{l}\text { TDM4258g, } \\
\text { phase II }\end{array}$ & 112 & $\begin{array}{l}\geq 1 \text { HER2-directed therapy } \\
\text { and } \geq 1 \text { chemotherapy for MBC }\end{array}$ & $3.6 \mathrm{mg} / \mathrm{kg} \mathrm{q} 3 \mathrm{w}$ & $\begin{array}{l}\text { Frequent sampling in cycles } \\
1 \text { and } 4 \text { for NCA of PK data; } \\
\text { peak/trough PK sampling in } \\
\text { subsequent cycles }\end{array}$ \\
\hline $\begin{array}{l}\text { TDM4374g, } \\
\text { phase II }\end{array}$ & 110 & $\begin{array}{l}\text { Trastuzumab, lapatinib, capecitabine, } \\
\text { a taxane, an anthracycline; } \\
\geq 2 \text { HER2-directed } \\
\text { therapies for MBC }\end{array}$ & $3.6 \mathrm{mg} / \mathrm{kg} \mathrm{q} 3 \mathrm{w}$ & $\begin{array}{l}\text { Frequent sampling in cycles } \\
1 \text { and } 4 \text { for NCA of PK; } \\
\text { peak/trough PK sampling in } \\
\text { subsequent cycles }\end{array}$ \\
\hline $\begin{array}{l}\text { TDM4688g, } \\
\text { phase II }\end{array}$ & 51 & Trastuzumab & $\begin{array}{l}\text { T-DM1 at up to } 3.6 \mathrm{mg} / \mathrm{kg} \\
\mathrm{q} 3 \mathrm{w} \text { for } 1 \text { year }^{\mathrm{a}}\end{array}$ & $\begin{array}{l}\text { Frequent sampling in cycles } \\
1 \text { and } 3 \text { for NCA of PK data; } \\
\text { QTc assessment pre- and } \\
\text { post-T-DM1 dosing }\end{array}$ \\
\hline
\end{tabular}

In all studies, the analytes measured were T-DM1, total trastuzumab, and DM1; incidence of anti-therapeutic antibodies to T-DM1 was also examined

A population PK analysis was conducted using T-DM1 PK data for all studies except TDM4688g

$H E R 2$ human epidermal growth factor receptor 2; $M B C$ metastatic breast cancer; $N C A$ noncompartmental analysis; $P K$ pharmacokinetic; $q 3 w$ every 3 weeks; $Q T C$ corrected QT; T-DM1 trastuzumab emtansine

${ }^{a}$ The earliest a patient could begin treatment with T-DM1 in combination with pertuzumab was cycle 4, day 1 , after all PK samples for singleagent T-DM1 had been obtained in cycle 3. Pertuzumab dose: 840-mg loading dose, followed by $420 \mathrm{mg}$ q3w for 1 year

interval [21]. PK analysis is a secondary objective. An additional exploratory objective is to detect and quantify the catabolites MCC-DM1 and Lys-MCC-DM1 in patients' plasma samples; these catabolites were first identified in preclinical studies as potentially relevant catabolites of T-DM1.

Assays for T-DM1, total trastuzumab, DM1, MCC-DM1, and Lys-MCC-DM1

Given the biochemical structure and complexity of T-DM1, multiple analytes were measured across the four studies to characterize the PK, including (but not limited to) the primary analyte, T-DM1, and other analytes such as total trastuzumab (TT; T-DM1 conjugate plus unconjugated trastuzumab) and DM1 (cytotoxic agent). T-DM1 and TT concentrations in serum were quantified using validated enzyme-linked immunosorbent assays (ELISAs) (described in Krop et al. [13]). DM1 concentrations in plasma were determined by Xendo Drug Development B.V. (Groningen, the Netherlands) using a validated liquid chromatography tandem mass spectrometry (LC-MS/MS) method developed by Genentech USA [13].

A LC-MS/MS assay was developed for exploratory analysis of catabolites MCC-DM1 and Lys-MCC-DM1 at Genentech. These catabolites were extracted from plasma by protein precipitation. The assay had a lower limit of quantifi- cation of $1.95 \mathrm{nM}(1.90 \mathrm{ng} / \mathrm{mL})$ and $0.976 \mathrm{nM}(1.08 \mathrm{ng} / \mathrm{mL})$ for MCC-DM1 and Lys-MCC-DM1, respectively.

Cross-study PK analyses

Noncompartmental analyses were conducted wherever possible. For patients with evaluable PK data, standard noncompartmental methods were used to calculate parameters at cycles 1 and 3 or 4 (at steady state), using WinNonLin ${ }^{\circledR}$ 5.2.1 in the Pharsight ${ }^{\circledR}$ Knowledgebase Server ${ }^{\mathrm{TM}}$.

Data from studies TDM3569g, TDM4258g, and TDM4374g were included in the population PK analysis, whereas the noncompartmental analysis (NCA) was conducted individually for each of the four studies. Population PK was best described by a linear two-compartment model, as described by Gupta et al. [22].

Assessment of exposure-efficacy and exposure-safety relationships

The relationships between T-DM1, TT, and DM1 exposure (area under the curve [AUC], maximum concentration $\left[C_{\max }\right]$, and minimum concentration $\left[C_{\min }\right]$ for T-DM1 and TT; $C_{\max }$ for DM1) and efficacy and safety were evaluated. For exposure-efficacy analyses, relationships between Bayesian post hoc PK parameter estimates obtained from 
the population PK analysis [22] and objective responses were assessed in patients receiving T-DM1 in TDM4258g and TDM4374g. Similar assessments were conducted with NCA parameter estimates obtained using TT and DM1 PK parameters. Data from dose-escalation and QTc studies were not used for exposure-efficacy analyses.

For exposure-safety analyses, correlations between T-DM1 exposure and levels of aspartate aminotransferase/ alanine aminotransferase (AST/ALT) and platelets were assessed in patients treated with T-DM1 in TDM3569g, TDM4258g, and TDM4374g. Post hoc estimates of T-DM1 exposure (AUC) obtained from population PK analysis were stratified into four quartiles, and time courses of these laboratory assessments (fifth and ninety-fifth percentiles, and individual data below the fifth percentile for platelet counts and above the ninety-fifth percentile for hepatic enzyme levels) were plotted across treatment cycles. In addition, T-DM1 exposure was compared in patients with and without post-dose grade $\geq 3$ transaminase elevations and/or thrombocytopenia.

\section{Anti-therapeutic antibodies to T-DM1}

Immunogenicity of T-DM1 was evaluated by measuring ATA responses to T-DM1 after repeated dosing in the four studies. ATA to T-DM1 were assessed in serum samples before the first T-DM1 dose and after subsequent T-DM1 doses, using a validated bridging antibody electrochemiluminescence assay (Bioveris ${ }^{\circledR}$, San Diego, CA) in TDM3569g and TDM4258g and by using a validated
ELISA (biotin- and digoxigenin-labeled T-DM1) in TDM4374g and TDM4688g. Samples were further analyzed by competitive-binding immunodepletion with T-DM1 and trastuzumab to confirm and characterize the ATA response. In addition, titer values were generated for positive samples. ATA-evaluable patients were those with at least one post-dose ATA sample. The ATA rate was defined as any patient with a positive response at any post-treatment time point divided by the total number of ATA-evaluable patients. Safety and efficacy implications, if any, were assessed for ATA-positive patients.

\section{Results}

Summaries of study designs, numbers of patients, and data sampling for TDM3569g, TDM4258g, TDM4374g, and TDM4688g are provided in Table 1. Baseline demographic and pathophysiologic characteristics were similar among the 288 patients who received $3.6 \mathrm{mg} / \mathrm{kg} \mathrm{q} 3 \mathrm{w}$ in the four studies (Table 2).

The concentration-time profiles and key PK parameters for the T-DM1 conjugate following a $\mathrm{q} 3 \mathrm{w}$ regimen across multiple dose levels in the phase I dose-escalation study are shown in Fig. 1a. Individual concentration-time curves for T-DM1 $3.6 \mathrm{mg} / \mathrm{kg} \mathrm{q3}$ w (MTD) after cycle 1 and at steady state for each phase II study are shown in Fig. 1b. Mean combined concentration-time profiles for T-DM1 conjugate, TT (a measure of T-DM1 conjugate plus unconjugated trastuzumab), and DM1 are shown in Fig. 1c.

Table 2 Demographic and baseline disease characteristics for patients enrolled in studies TDM3569g (3.6-mg/kg cohort), TDM4258g, TDM4374g, and TDM4688g

\begin{tabular}{llllll}
\hline Baseline characteristics & \multicolumn{2}{l}{ Median $($ range $)$} & & & \\
\cline { 2 - 6 } & $\begin{array}{l}\text { TDM3569g } \\
(n=15)\end{array}$ & $\begin{array}{l}\text { TDM4258g } \\
(N=112)\end{array}$ & $\begin{array}{l}\text { TDM4374g } \\
(N=110)\end{array}$ & $\begin{array}{l}\text { TDM4688g } \\
(N=51)\end{array}$ & $\begin{array}{l}\text { All studies } \\
(N=288)\end{array}$ \\
\hline Age $(\mathrm{y})$ & $50(35-65)$ & $54.5(33-82)$ & $52.5(34-77)$ & $52(34-85)$ & $53(33-85)$ \\
Weight $(\mathrm{kg})$ & $65.2(49.9-93.8)$ & $70.0(37.7-137)$ & $69.7(38.5-136)$ & $67.2(44-105)$ & $69.1(37.7-137)$ \\
Height $(\mathrm{cm})$ & $164(146-173)$ & $163(128-178)$ & $163(145-188)$ & $165(145-181)$ & $163(128-188)^{\mathrm{a}}$ \\
Body mass index $\left(\mathrm{kg} / \mathrm{m}^{2}\right)$ & $26.1(16.7-32.8)$ & $26.4(14.7-52.9)$ & $26.1(17.1-44.1)$ & $26.1(17.3-42.4)$ & $26.1(14.7-52.9)^{\mathrm{a}}$ \\
Body surface area $\left(\mathrm{m}^{2}\right)$ & $1.70(1.48-2.05)$ & $1.76(1.33-2.39)$ & $1.76(1.29-2.40)$ & $1.76(1.38-2.14)$ & $1.76(1.29-2.40)^{\mathrm{a}}$ \\
Aspartate aminotransferase $(\mathrm{IU} / \mathrm{L})$ & $28(14-100)$ & $32.8(13.5-227)$ & $29.3(13.5-140)$ & N/A & $30.8(13.5-227)^{\mathrm{b}}$ \\
Alanine aminotransferase $(\mathrm{IU} / \mathrm{L})$ & $26.5(9.5-173)$ & $29.6(8-111)$ & $24(9-170)$ & N/A & $26(8-173)^{\mathrm{b}}$ \\
Platelet count $\left(10^{3} / \mu \mathrm{L}\right)$ & $243(143-354)$ & $263(127-569)$ & $249(0.2-886)$ & N/A & $252(112-886)^{\mathrm{b}}$ \\
Circulating HER2 ECD $(\mathrm{ng} / \mathrm{mL})$ & $24(6.3-86.8)$ & $30.1(5-560)$ & $30.1(5.9-560)$ & N/A & $30.1(5-560)^{\mathrm{b}}$ \\
Trastuzumab $(\mu \mathrm{g} / \mathrm{mL})$ & $6.2(0.04-72.9)$ & $0.04(0.04-66.9)$ & $0.11(0.04-122)$ & $1.88(0-148)$ & $0.05(0-148)$ \\
\hline
\end{tabular}

ECD extracellular domain; HER2 human epidermal growth factor receptor 2; N/A not available

a $n=287$ patients

${ }^{\mathrm{b}}$ Final data for patients in study TDM4688g were not available; $n=237$ patients 


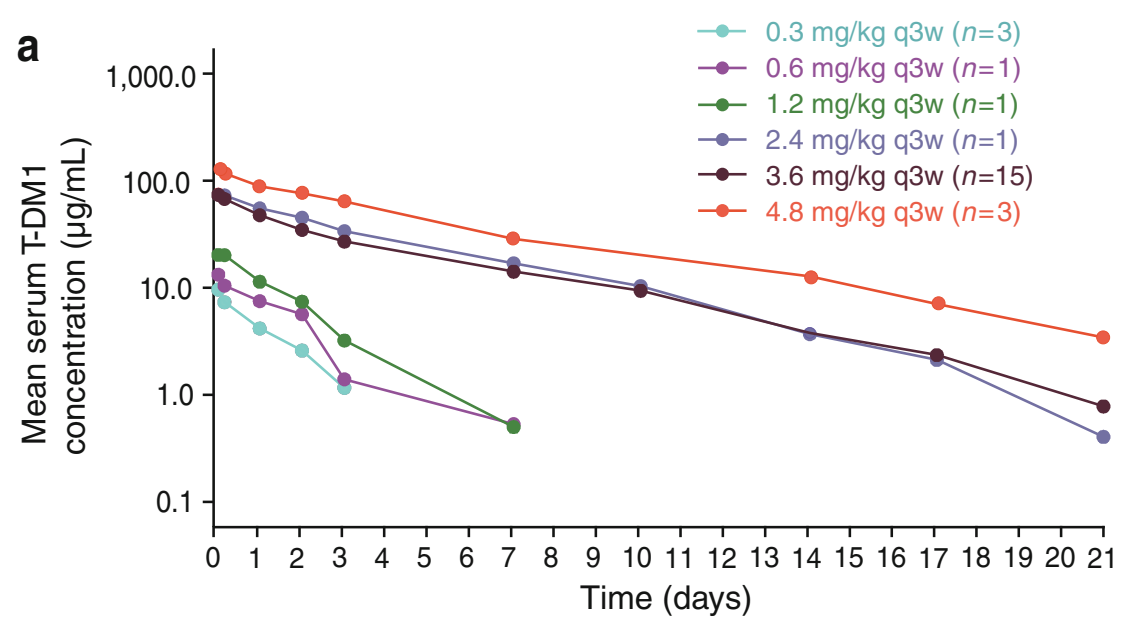

\begin{tabular}{l|ccccc}
\hline & \multicolumn{3}{|c}{ Mean (standard deviation) } \\
\hline $\begin{array}{l}\text { Dosing regimen } \\
(\mathrm{mg} / \mathrm{kg}) \mathrm{q} 3 \mathrm{w}\end{array}$ & $\begin{array}{c}C_{\max } \\
(\mu \mathrm{g} / \mathrm{mL})\end{array}$ & $\begin{array}{c}\mathrm{AUC}_{\text {inf }} \\
(\text { day } \bullet \mu \mathrm{g} / \mathrm{mL})\end{array}$ & $\begin{array}{c}\text { Elimination } \\
t_{1 / 2}(\text { day })\end{array}$ & $\begin{array}{c}V_{\text {ss }} \\
(\mathrm{mL} / \mathrm{kg})\end{array}$ & $\begin{array}{c}\text { Clearance } \\
(\mathrm{mL} / \mathrm{day} / \mathrm{kg})\end{array}$ \\
\hline $0.3(n=3)$ & $9.63(1.73)$ & $14.5(3.4)$ & $1.3(0.2)$ & $35.7(7.5)$ & $21.1(4.5)$ \\
$0.6(n=1)$ & 13.3 & 24.5 & 1.3 & 43.8 & 24.5 \\
$1.2(n=1)$ & 20.3 & 42.9 & 1.3 & 51.8 & 27.8 \\
$2.4(n=1)$ & 76.3 & 330 & 2.2 & 30.7 & 7.16 \\
$3.6(n=15)$ & $76.2(19.1)$ & $300(66)$ & $3.1(0.7)$ & $58.4(12.4)$ & $12.7(3.6)$ \\
$4.8(n=3)$ & $130(8)$ & $673(12)$ & $4.1(0.7)$ & $41.2(6.2)$ & $7.13(0.13)$ \\
\hline
\end{tabular}

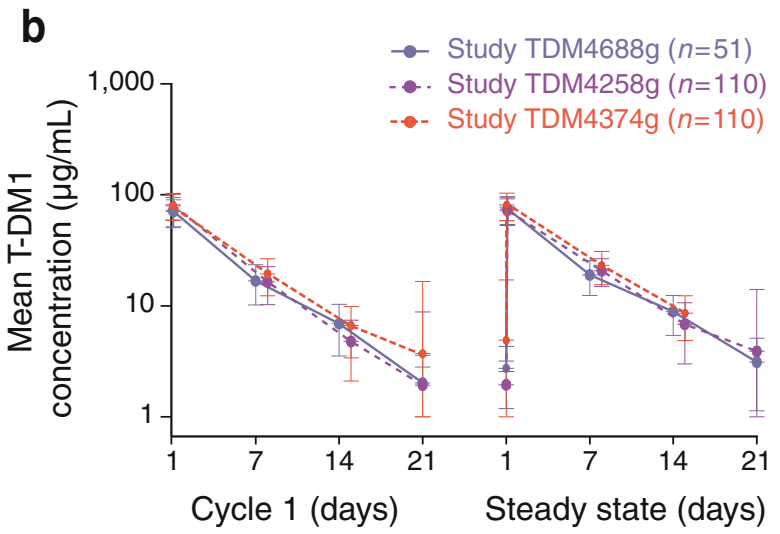

Fig. 1 a Serum trastuzumab emtansine (T-DM1) concentration-time curves and pharmacokinetic parameters by dose level in the T-DM1 dose-escalation study TDM3569g after every-3-week (q3w) dosing. b Concentration-time curves for T-DM1 in cycle 1 and at steady state after T-DM1 dosing in TDM4258g, TDM4374g, and TDM4688g. c Mean concentration profiles combining three phase II studies

Relevant NCA estimates for the PK parameters $C_{\max }$, AUC, terminal half-life $\left(t_{1 / 2}\right)$, steady-state volume of distribution $\left(V_{\mathrm{ss}}\right)$, and clearance are summarized in Table 3 for T-DM1, TT, and DM1 in patients who received T-DM1 at a dose of $3.6 \mathrm{mg} / \mathrm{kg} \mathrm{q} 3 \mathrm{w}$ in the phase I and II studies.

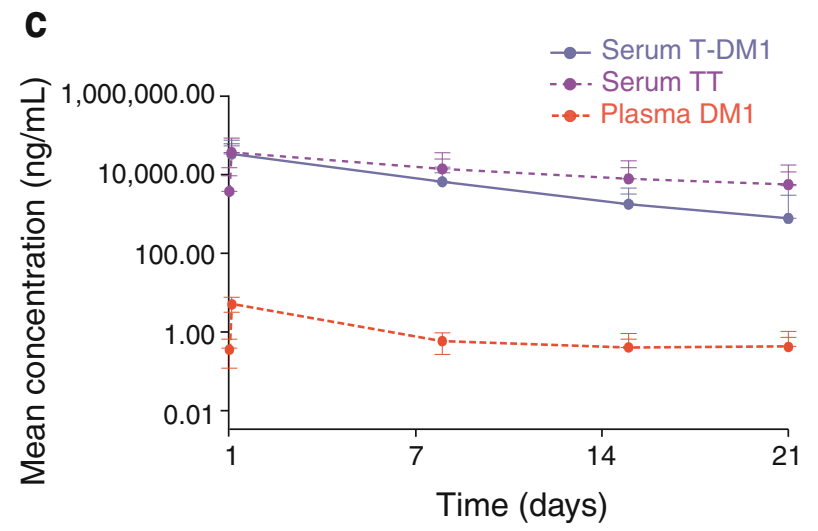

(TDM4258g, TDM4374g, and TDM4688g) after first dose of T-DM1. $\mathrm{AUC}_{\text {inf }}$, area under the curve from time 0 extrapolated to infinity; $C_{\max }$, maximum concentration; $t_{1 / 2}$, terminal half-life; TT, total trastuzumab (T-DM1 plus unconjugated trastuzumab); $V_{\text {ss }}$, steady-state volume of distribution

Phase I study results

The dose levels evaluated in the phase I dose-escalation study for the $\mathrm{q} 3 \mathrm{w}$ regimen ranged from 0.3 to $4.8 \mathrm{mg} / \mathrm{kg}$. For q3w T-DM1 dosing, systemic exposure of T-DM1, as measured using $C_{\max }$ and AUC, increased linearly with 
Table 3 Serum trastuzumab emtansine (T-DM1), serum total trastuzumab (TT), and plasma DM-1 pharmacokinetic (PK) parameters for patients in studies TDM3569g (3.6-mg/kg cohort), TDM4258g, TDM4374g, and TDM4688g

\begin{tabular}{|c|c|c|c|c|c|c|}
\hline \multirow[t]{2}{*}{ Analyte } & \multirow{2}{*}{$\begin{array}{l}\text { Study (no. } \\
\text { of patients }^{\mathrm{a}} \text { ) }\end{array}$} & \multicolumn{5}{|c|}{ Mean (standard deviation) } \\
\hline & & $\begin{array}{l}C_{\max } \\
(\mu \mathrm{g} / \mathrm{mL})\end{array}$ & $\begin{array}{l}\mathrm{AUC}_{\mathrm{inf}} \\
(\text { day } \mu \mathrm{g} / \mathrm{mL})\end{array}$ & $t_{1 / 2}$ (day) & $V_{\mathrm{ss}}(\mathrm{mL} / \mathrm{kg})$ & $\begin{array}{l}\text { Clearance } \\
(\mathrm{mL} / \mathrm{day} / \mathrm{kg})\end{array}$ \\
\hline \multirow[t]{4}{*}{ Serum T-DM1 } & TDM3569g $(n=15)$ & $76.2(19.1)$ & $300(65.8)$ & $3.1(0.7)$ & $58.4(12.4)$ & $12.7(3.56)$ \\
\hline & TDM4258g $(n=101)$ & $80.9(20.7)$ & 457 (129) & $3.53(0.71)$ & $28.4(12.9)$ & $8.51(2.69)$ \\
\hline & TDM4374g $(n=105)$ & $79.5(21.1)$ & $486(141)$ & $3.96(0.96)$ & $31.2(10.9)$ & $8.04(2.97)$ \\
\hline & TDM4688g $(n=51)$ & $75.6(21.9)$ & $431(126)$ & $4.02(0.94)$ & $41.2(24.5)$ & $9.17(3.03)$ \\
\hline \multirow[t]{4}{*}{ Serum TT } & TDM3569g $(n=15)$ & $110(40.3)$ & $1,144(857)$ & $9.1(4.9)$ & $50.7(19.7)$ & $4.90(3.23)$ \\
\hline & TDM4258g $(n=101)$ & $88.0(30.2)$ & $1,040(1,030)$ & $9.2(10.9)$ & $46.5(58.4)$ & $5.64(6.30)$ \\
\hline & TDM4374g $(n=105)$ & $89.9(31.3)$ & $1,150(852)$ & $9.38(4.90)$ & $43.2(16.3)$ & $4.55(2.64)$ \\
\hline & TDM4688g $(n=51)$ & $95.9(32.3)$ & $1,420(1,390)$ & $10.3(6.8)$ & $41.9(16.2)$ & $4.21(2.43)$ \\
\hline Analyte & \multicolumn{5}{|c|}{ Study (no. of patients ${ }^{\mathrm{a}}$ ) } & $\begin{array}{l}C_{\max } \text { at cycle } 1 \\
(\mathrm{ng} / \mathrm{mL})\end{array}$ \\
\hline \multirow[t]{4}{*}{ Plasma DM1 ${ }^{\mathrm{b}}$} & \multicolumn{5}{|c|}{ TDM3569g $(n=15)$} & $4.57(1.33)$ \\
\hline & \multicolumn{5}{|c|}{ TDM4258g $(n=101)$} & $5.35(2.03)$ \\
\hline & \multicolumn{5}{|c|}{ TDM4374g $(n=105)$} & $5.36(2.56)$ \\
\hline & \multicolumn{5}{|c|}{ TDM4688g $(n=51)$} & $5.42(1.62)$ \\
\hline
\end{tabular}

$\overline{A U C_{i n f} \text { area under the serum concentration versus time curve from time } 0 \text { extrapolated to infinity; } C_{\max } \text { maximum observed concentration; } P K}$ pharmacokinetic; $V_{s s}$ volume of distribution at steady state; $t_{1 / 2}$ terminal half-life

${ }^{a}$ Number of patients with at least one PK parameter evaluable

b Plasma DM1 concentrations were below the limit of quantification at the majority of time points and, therefore, no formal PK analysis was possible

increasing doses $\geq 2.4 \mathrm{mg} / \mathrm{kg}$ (see Fig. 1a). Higher T-DM1 clearance was observed at doses of $\leq 1.2 \mathrm{mg} / \mathrm{kg}$, with mean clearance values ranging from 21.1 to $27.8 \mathrm{~mL} /$ day $/ \mathrm{kg}$. Thus, linearity was established for doses $\geq 2.4 \mathrm{mg} / \mathrm{kg}$. The assessment of dose linearity was limited by the number of patients evaluated per dose level, especially at doses $<3.6 \mathrm{mg} / \mathrm{kg}$. After T-DM1 dosing, TT concentrations declined more slowly than the levels of T-DM1 did. Mean concentrations of DM1 were consistently low (mean, $4.57 \pm 1.33 \mathrm{ng} / \mathrm{mL}$ ) and declined to below the lower limit of quantification within a few days after dosing.

Phase II study results

All PK parameters $\left(C_{\mathrm{max}}, \mathrm{AUC}, t_{1 / 2}, V_{\mathrm{ss}}\right.$, and clearance) for serum T-DM1, serum TT, and plasma DM1 were consistent at cycle 1, as well as at steady state (cycles 3 or 4), across studies. No significant accumulation of T-DM1 was observed with $\mathrm{q} 3 \mathrm{w}$ dosing in any of the studies (see Fig. 1b). Across the studies, TT had a longer $t_{1 / 2}$ than that of T-DM1. T-DM1 PK parameters were not affected by baseline trastuzumab levels or by baseline HER2 ECD. In all three phase II studies, plasma DM1 concentrations were low, with no observed accumulation over treatment cycles. The highest reported concentration of DM1 was $25 \mathrm{ng} / \mathrm{mL}$ in study TDM4374g; in the majority of samples, especially at later time points, the DM1 concentration was below the lower limit of quantification of $0.737 \mathrm{ng} / \mathrm{mL}$. A consistently low DM1 exposure after T-DM1 administration was observed immediately after dosing.

The average $C_{\max }$ of DM1 was $5.35 \pm 2.03,5.36 \pm 2.56$, and $5.42 \pm 1.62 \mathrm{ng} / \mathrm{mL}$ in TDM4258g, TDM4374g, and TDM4688g, respectively.

In study TDM4688g, patient plasma was sampled and analyzed for the T-DM1 catabolites Lys-MCC-DM1 and MCC-DM1 in addition to T-DM1, TT, and DM1. At $1 \mathrm{~h}$ after infusion in cycle 1 , the mean concentrations of MCC-DM1 (34.4 ng/mL; range, 6.47-122 ng/mL) and LysMCC-DM1 (1.35 ng/mL; range $1.25-1.45 \mathrm{ng} / \mathrm{mL}$ ) were low. Similar mean values were seen $1 \mathrm{~h}$ after infusion in cycle 3 . No significant accumulation was observed in systemic circulation for the linker/DM1-containing catabolites of T-DM1.

Exposure-efficacy relationship

T-DM1 exposures (AUC and $C_{\max }$ ) were generally similar among patients with an objective response (i.e., a complete response or a partial response), progressive disease, or stable disease (Fig. 2a, b). No significant correlations were observed between activity (as measured by objective response and Response Evaluation Criteria in Solid Tumors v1.0) and T-DM1 exposure following dosing at $3.6 \mathrm{mg} / \mathrm{kg} \mathrm{q} 3 \mathrm{w}$ across the phase II studies (TDM4258g and TDM4374g). 
Fig. 2 a Serum trastuzumab emtansine (T-DM1) area under the concentration-time curve (AUC) by response in patients in studies TDM4374g and TDM4258g. b Serum T-DM1 maximum concentration $\left(C_{\max }\right)$ by response in patients in studies TDM4374g and TDM4258g.

c Baseline circulating human epidermal growth factor receptor 2 (HER2) extracellular domain (ECD) by response in patients in studies TDM4374g and TDM4258g. d TT AUC last $_{\text {by }}$ response in patients in studies TDM4374g and TDM4258g. $\mathrm{AUC}_{\text {last }}$, area under the concentration-time curve in the last sample drawn; $P D$ progressive disease, $P R$ partial response, $S D$ stable disease, $T T$ total trastuzumab (T-DM1 plus unconjugated trastuzumab)
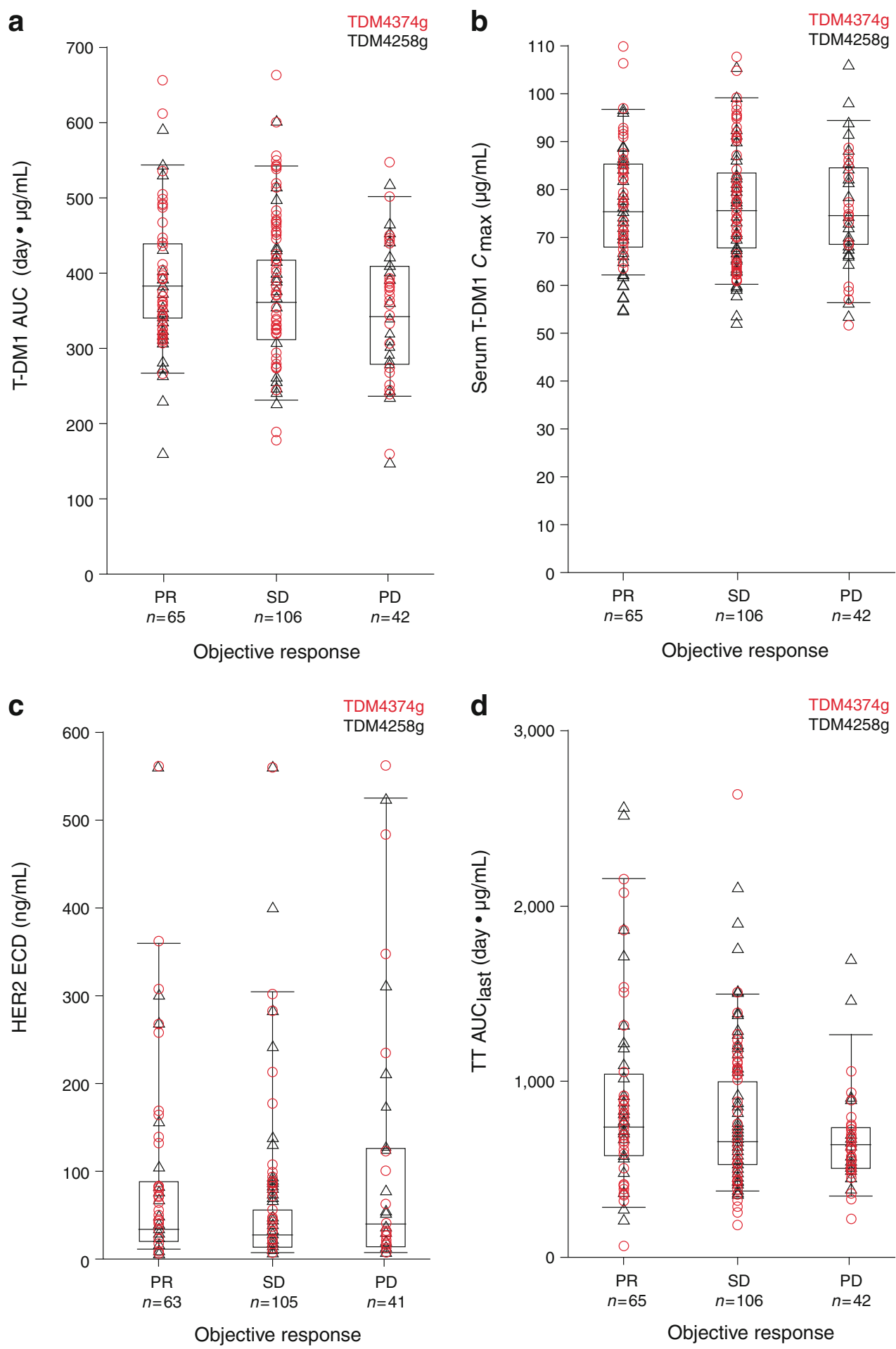

Effects of HER2 ECD and baseline trastuzumab levels on response rates

The presence of baseline circulating HER2 ECD had no apparent effect on response rate (Fig. 2c). The serum TT concentration at baseline (pre-T-DM1 dose) measures trastuzumab in circulation from prior trastuzumab treatment. TT concentrations, post T-DM1 infusion, reflect trastuzumab from prior treatment plus T-DM1 conjugate plus trastuzumab resulting from T-DM1 deconjugation. As expected, TT AUC in cycle 1 was higher in patients with higher baseline trastuzumab concentrations; this also had no effect on response rate (Fig. 2d). 
Exposure-safety relationship

In the phase I study [13], the MTD for T-DM1 monotherapy $\mathrm{q} 3 \mathrm{w}$ was established at $3.6 \mathrm{mg} / \mathrm{kg}$ on the basis of the DLT of grade 4 thrombocytopenia that was observed in two of three patients who received T-DM1 at $4.8 \mathrm{mg} / \mathrm{kg}$. A dose-dependent decline in platelet count was observed, with nadirs observed around 8 days after T-DM1 administration and recovery observed by about 15 days. Variability in the degree of thrombocytopenia occurred among individual patients [23]. Additionally, many patients had serum transaminase increases based on National Cancer Institute Common Terminology Criteria for Adverse Events v3.0 guidelines.

Across three studies (TDM3569g, TDM4258g, and TDM4374g), laboratory data on serum transaminases were available for 237 patients. Relative to the baseline, 19 patients had a grade 3 increase in serum AST, and one patient had a grade 4 increase. Increases in serum ALT, often a more specific indicator of hepatotoxicity than increases in AST, were less common, with nine patients having a grade 3 increase and one patient having a grade 4 increase. No adverse events potentially related to abnormalities in hepatic synthetic function (i.e., hypoalbuminemia or coagulopathy) were observed.

Given the increased frequency of these adverse events, exposure-safety relationships with platelet, ALT, and AST levels were examined. No obvious relationship between T-DM1 exposure (by AUC quartiles) and thrombocytopenia or changes in serum concentrations of AST or ALT was observed during the course of T-DM1 treatment across the phase II studies (Fig. 3a-c). Similar results were observed for circulating TT and DM1 exposure parameters (data not shown). No obvious relationship between T-DM1 AUCs and the presence or absence of grade 3 thrombocytopenia was observed (mean AUC \pm standard deviation [SD], $369 \pm 78$ day $\mu \mathrm{g} / \mathrm{mL}$ vs. $369 \pm 96$ day $\mu \mathrm{g} / \mathrm{mL}$, respectively). Similarly, no correlations between T-DM1 AUCs and the presence or absence of grade 3 increases in ALT (mean $\mathrm{AUC} \pm \mathrm{SD}, 397 \pm 168$ day $\mu \mathrm{g} / \mathrm{mL}$ vs. $368 \pm 90$ day $\mu \mathrm{g} /$ $\mathrm{mL}$, respectively) or $\mathrm{AST}$ (mean $\mathrm{AUC} \pm \mathrm{SD}, 391 \pm 136$ day $\mu \mathrm{g} / \mathrm{mL}$ vs. $367 \pm 89$ day $\mu \mathrm{g} / \mathrm{mL}$, respectively) were observed. Similar results were obtained for $C_{\max }$ and $C_{\min }$ (data not shown).

Anti-therapeutic antibody response to T-DM1

Across the four studies, 13 of 286 patients treated with TDM1 $3.6 \mathrm{mg} / \mathrm{kg}$ q3w were evaluable for ATA response. ATA formation was observed in $4.5 \%$ (13 of 286) of these patients. This response was confirmed by competitive-binding immunodepletion with T-DM1 (data not shown). No obvious patterns were observed in the PK, safety profiles, or efficacy outcomes of patients who developed antibodies to T-DM1 compared with those who tested negative for antibodies to T-DM1.

\section{Discussion}

Antibody-drug conjugates (ADCs) such as T-DM1 are complex molecules composed of both small (DM1) and large (trastuzumab) components. Therefore, a unique and customized clinical pharmacology strategy to specifically address patient safety and efficacy following administration of T-DM1 was employed; the results of this analysis are reported here. Two key bioanalytical methodologies typically used for large and small molecule quantification, ELISA and LC-MS/MS, respectively, were used to measure the PK parameters of multiple analytes across phase I and phase II studies. Validated PK assays were used to measure T-DM1, TT, and DM1, while exploratory LC-MS/ MS assays were developed to measure linker/DM1-containing catabolites, such as MCC-DM1 and Lys-MCCDM1, in plasma samples. Exposure-response (safety/ efficacy) analyses were also conducted. Finally, the potential for immunogenicity was evaluated using a tiered approach, in which ATA responses to all the molecular components of the ADC were measured. Additional results from the evaluation of clinical pharmacology of T-DM1 are reported elsewhere and include a population $\mathrm{PK}$ assessment of demographic and pathophysiologic covariates likely to impact the clearance of T-DM1 [22], the potential for T-DM1-induced QT interval prolongation [21], and the potential for drug interaction [24, 25]. An integrated modeling and simulation strategy has also been implemented to better understand the PK and pharmacodynamic relationships with T-DM1 [22, 23, 26].

In the analysis reported here, a trend toward faster clearance was observed at T-DM1 doses of $\leq 1.2 \mathrm{mg} / \mathrm{kg}$ in the phase I study TDM3569g; however, across doses ranging from 2.4 to $4.8 \mathrm{mg} / \mathrm{kg}$ q3w, T-DM1 exhibited linear PK. These results, though limited, suggest that the clearance of T-DM1 occurs via dual mechanisms (i.e., target [HER2] antigen-specific and nonspecific [e.g., Fc-mediated] mechanisms), similar to the clearance mechanisms observed with other humanized antibodies [27]. Across studies, the PK profile of $3.6 \mathrm{mg} / \mathrm{kg}$ q3w, T-DM1 was characterized by mean clearance values ranging from 7 to $13 \mathrm{~mL} / \mathrm{day} / \mathrm{kg}$, a volume of distribution limited to the plasma volume and a $t_{1 / 2}$ of approximately 4 days, which likely explains the observation in all four studies that repeated dosing of T-DM1 $\mathrm{q} 3 \mathrm{w}$ did not result in any noticeable accumulation of T-DM1. TT was found to have a slower clearance (approximately 3-6 mL/day/kg) and longer $t_{1 / 2}$ (approximately 9-11 days) compared with T-DM1. As T-DM1 is a mixture composed of trastuzumab with 0-8 DM1 molecules, it is hypothesized 
Fig. 3 a Platelet, b aspartate aminotransferase (AST), and c alanine aminotransferase (ALT) time courses (fifth and ninety-fifth percentiles) at each time point during the course of trastuzumab emtansine treatment at $3.6 \mathrm{mg} / \mathrm{kg}$ every 3 weeks stratified by area under the concentration-time curve (AUC) quartile $(\mathrm{Q})$ in studies

TDM3569g, TDM4258g, and TDM4374g. Red bars, 95\% confidence intervals; blue circles, patient values below the fifth (platelets) or above the ninetyfifth (AST, ALT) percentile; black dashed line, cutoff for grade 3 or greater adverse event $(>5 \times$ upper limit of normal (ULN) for AST and ALT; $<50,000$ platelet counts)

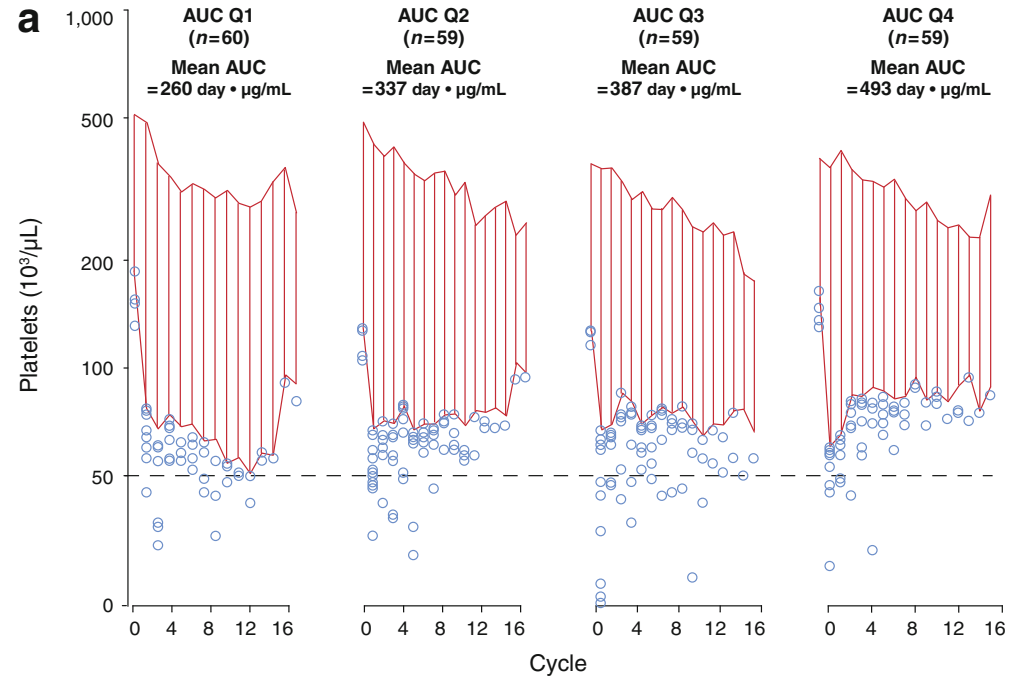

b
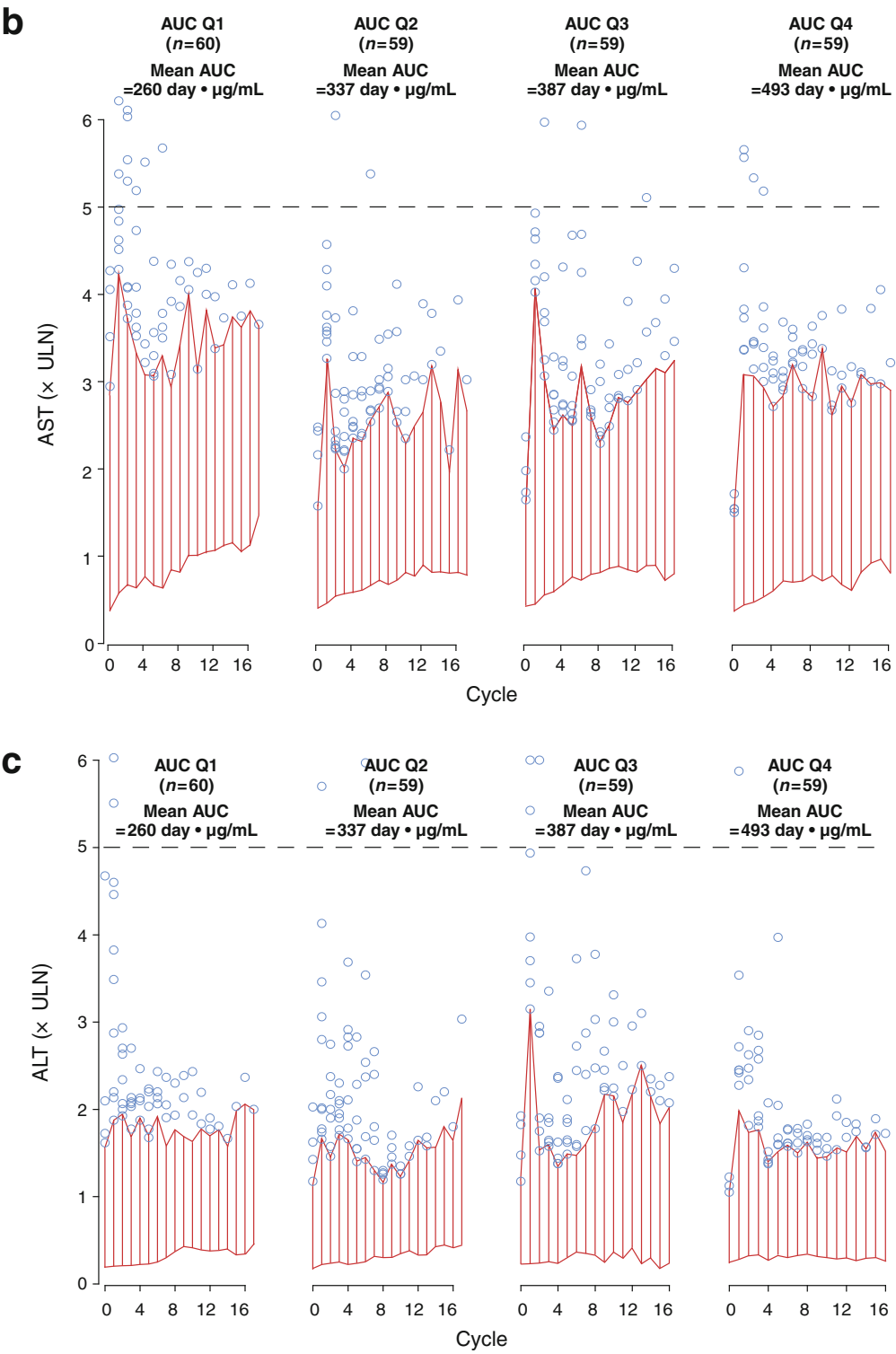
that T-DM1 is mainly cleared by deconjugation (during which higher drug-to-antibody ratio [DAR] species are converted to lower DAR species and unconjugated trastuzumab) and proteolytic degradation. The faster clearance of T-DM1 relative to TT may be explained by the combined clearance mechanisms for T-DM1 [28].

The consistently low maximum systemic plasma DM1 concentrations (with an average $\sim 5 \mathrm{ng} / \mathrm{mL}$ at a T-DM1 dose of $3.6 \mathrm{mg} / \mathrm{kg}$ ) demonstrated the stability of the T-DM1 linker MCC. Additionally, no evidence of DM1 accumulation in plasma was observed after repeated dosing of T-DM1; across all studies, maximum DM1 concentrations did not exceed $25 \mathrm{ng} / \mathrm{mL}$ in individual patients after repeated administration of T-DM1.

In an exploratory analysis of T-DM1 catabolites, low concentrations of MCC-DM1 (<1.90-122 ng/mL) and Lys-MCC-DM1 (<1.08-6.4 ng/mL) were observed. These catabolites were also present in plasma, urine, and bile samples obtained after the administration of radiolabeled T-DM1 to rats, further confirming the utility of the rat model for assessing T-DM1 catabolism [29]. In the clinical samples, no evidence of DM1, MCC-DM1, or Lys-MCCDM1 accumulation was observed after repeated dosing of T-DM1. Given the nature of exploratory metabolite analysis, it was not possible to comprehensively characterize the kinetics of catabolite/metabolite formation; however, two trends were apparent. In general, MCC-DM1 levels were found to peak immediately after dosing, and a lag time was associated with the formation of Lys-MCC-DM1, as higher levels of this catabolite were observed at later time points.

PK serum samples with rich sampling were obtained in the phase I study TDM3569g, and PK serum samples with relatively sparse sampling were obtained from the phase II studies TDM4258g, TDM4374g, and TDM4688g. In general, the NCA and population PK approaches provided good concordance of PK estimates [22]; however, a systematic bias appears to exist with the NCA approach for AUC estimates. On average, the AUC was 20\% higher based on the NCA of the phase II studies compared with that obtained using the population PK approach. This difference was attributed partly to the sparse sampling, which does not capture the distribution phase of T-DM1.

In a previously reported population $\mathrm{PK}$ analysis of T-DM1 [22], there was no evidence to suggest that the markers of liver function (e.g., AST, ALT, total bilirubin, and albumin) and renal function (e.g., calculated creatinine clearance) have a clinically meaningful effect on the PK of T-DM1. Further, in the exposure-safety analysis reported here, T-DM1 total exposures (AUC) were compared between patients with and without grade $\geq 3$ ALT/AST elevations after T-DM1 treatment, and no differences in T-DM1 AUC values were observed. While the data presented here suggest that hepatic and renal function are unlikely to affect the systemic exposure of T-DM1, it should be noted that patients with moderate to severe liver impairment were excluded in these trials and that the DM1 component of T-DM1 is primarily metabolized and eliminated as DM1containing catabolites through the biliary route [29]. A clinical study is needed to fully understand the relationship of varying degrees of liver impairment on the PK, safety, and appropriate dosing of T-DM1.

Dose-limiting, transient grade 4 thrombocytopenia was observed with the T-DM1 regimen of $4.8 \mathrm{mg} / \mathrm{kg} \mathrm{q} 3 \mathrm{w}$ but not with T-DM1 $3.6 \mathrm{mg} / \mathrm{kg} \mathrm{q3w}$ in a phase I study (TDM3569g); no other dose level between 3.6 and $4.8 \mathrm{mg} /$ $\mathrm{kg}$ was tested. To determine whether there is a relationship between T-DM1 exposure and platelet declines, platelet counts in patients treated with T-DM1 $3.6 \mathrm{mg} / \mathrm{kg}$ were monitored in subsequent studies (TDM4258g and TDM4374g). Similar to the changes in AST/ALT, no obvious trend was observed between platelet declines and total exposure at a T-DM1 dose of $3.6 \mathrm{mg} / \mathrm{kg} \mathrm{q} 3 \mathrm{w}$.

Because both of the phase II studies-TDM4258g and TDM4374g-were conducted with a single T-DM1 dose (MTD of $3.6 \mathrm{mg} / \mathrm{kg}$ in a $\mathrm{q} 3 \mathrm{w}$ regimen), the relationship between T-DM1 exposure and response (partial response, stable disease, and progressive disease) was limited to a narrow range of T-DM1 exposure. Other covariates, specifically baseline trastuzumab and baseline HER2 ECD concentrations, did not affect T-DM1 PK or response rates significantly in this patient population.

Overall, ATA formation was observed in $4.5 \%$ (13 of 286) of patients after repeated dosing of T-DM1 $3.6 \mathrm{mg} / \mathrm{kg}$ $\mathrm{q} 3 \mathrm{w}$ across the four clinical studies. Although limited data are available to date, there appears to be no obvious effect of ATA on the PK, safety, or efficacy profiles of T-DM1. The clinical significance of antibody development against T-DM1 is unknown; however, no obvious changes were observed in the PK, safety profiles, or efficacy outcomes of patients who developed antibodies to T-DM1 compared with patients who tested negative for antibodies to T-DM1.

In conclusion, the PK profile (i.e., $C_{\max }, \mathrm{AUC}, t_{1 / 2}, V_{\mathrm{ss}}$, and clearance) of single-agent T-DM1 $(3.6 \mathrm{mg} / \mathrm{kg} \mathrm{q} 3 \mathrm{w})$ is predictable and well characterized, as demonstrated by its consistency across the four clinical studies included in this analysis. T-DM1 exposure at $3.6 \mathrm{mg} / \mathrm{kg}$ q3w does not correlate with clinical responses, and efficacy outcomes are not affected by circulating levels of HER2 ECD or residual trastuzumab (from previous trastuzumab therapy). A relationship does not appear to exist between T-DM1 exposure and the incidence of grade 3 thrombocytopenia or grade 3 elevations in levels of ALT or AST when given at this dose regimen. The incidence of ATAs is low (4.5\%) in patients exposed to repeated doses of T-DM1. 
Acknowledgments The investigators would like to thank all of the patients who participated in the clinical trials and their families. They would also like to thank Drs B Klencke and S Agresta for support with phase II study design and implementation. Support for third-party writing assistance for this manuscript was provided by Genentech, Inc.

Conflicts of interest S.G., M.G., B.W., D.L., J-H Y., O.S., B.T., Y.-W. C., S.H., and A.J. are employees of Genentech, Inc. I.K. has received research funding from Genentech, Inc. C.L.V. has served on advisory boards for Genentech, Inc. and has been an expert witness for F. Hoffman-La Roche Ltd. The Sylvester Comprehensive Cancer Center (C.L.V.'s institution) has received research funding from Genentech, Inc. P.M.L. has received honoraria from Genentech, Inc.

Open Access This article is distributed under the terms of the Creative Commons Attribution Noncommercial License which permits any noncommercial use, distribution, and reproduction in any medium, provided the original author(s) and source are credited.

\section{References}

1. Slamon DJ, Clark GM, Wong SG, Levin WJ, Ullrich A, McGuire WL (1987) Human breast cancer: correlation of relapse and survival with amplification of the HER-2/neu oncogene. Science 235:177-182

2. Dawood S, Broglio K, Buzdar AU, Hortobagyi GN, Giordano SH (2010) Prognosis of women with metastatic breast cancer by HER2 status and trastuzumab treatment: an institutional-based review. J Clin Oncol 28:92-98

3. Romond EH, Perez EA, Bryant J, Suman VJ, Geyer CE Jr, Davidson NE, Tan-Chiu E, Martino S, Paik S, Kaufman PA, Swain SM, Pisansky TM, Fehrenbacher L, Kutteh LA, Vogel VG, Visscher DW, Yothers G, Jenkins RB, Brown AM, Dakhil SR, Mamounas EP, Lingle WL, Klein PM, Ingle JN, Wolmark N (2005) Trastuzumab plus adjuvant chemotherapy for operable HER2-positive breast cancer. N Engl J Med 353:1673-1684

4. Marty M, Cognetti F, Maraninchi D, Snyder R, Mauriac L, Tubiana-Hulin M, Chan S, Grimes D, Antón A, Lluch A, Kennedy J, O'Byrne K, Conte P, Green M, Ward C, Mayne K, Extra JM (2005) Randomized phase II trial of the efficacy and safety of trastuzumab combined with docetaxel in patients with human epidermal growth factor receptor 2-positive metastatic breast cancer administered as first-line treatment: the M77001 study group. J Clin Oncol 23:4265-4274

5. von Minckwitz G, Vogel P, Schmidt M, Eidtmann H, Cufer T, de Jongh F, Maartense E, Zielinski C, Andersson M, Stein R, Neklijudova V, Loibl S (2007) Trastuzumab treatment beyond progression in patients with HER-2 positive metastatic breast cancer- the TBP study (GBG 26/BIG 3-05) [abstract 4056]. Breast Cancer Res Treat 106(suppl 1):S185

6. National Comprehensive Cancer Network Breast Cancer Guidelines, v2.2011. http://www.nccn.org/professionals/physician_gls/ pdf/breast.pdf. Accessed 29 August 2011

7. Cassady JM, Chan KK, Floss HG, Leistner E (2004) Recent developments in the maytansinoid antitumor agents. Chem Pharm Bull (Tokyo) 52:1-26

8. Remillard S, Rebhun LI, Howie GA, Kupchan SM (1975) Antimitotic activity of the potent tumor inhibitor maytansine. Science 189:1002-1005

9. Widdison WC, Wilhelm SD, Cavanagh EE, Whiteman KR, Leece BA, Kovtun Y, Goldmacher VS, Xie H, Steeves RM, Lutz RJ, Zhao R, Wang L, Blättler WA, Chari RV (2006) Semisynthetic maytansine analogues for the targeted treatment of cancer. J Med Chem 49:4392-4408
10. Junttila TT, Li G, Parsons K, Phillips GL, Sliwkowski MX (2011) Trastuzumab-DM1 (T-DM1) retains all the mechanisms of action of trastuzumab and efficiently inhibits growth of lapatinib insensitive breast cancer. Breast Cancer Res Treat 128:347-356

11. Kovtun YV, Audette CA, Mayo MF, Jones GE, Doherty H, Maloney EK, Erickson HK, Sun X, Wilhelm S, Ab O, Lai KC, Widdison WC, Kellogg B, Johnson H, Pinkas J, Lutz RJ, Singh R, Goldmacher VS, Chari RV (2010) Antibody-maytansinoid conjugates designed to bypass multidrug resistance. Cancer Res 70:2528-2537

12. Li G, Fields CT, Parsons KL, Guo J, Lewis Phillips GD (2010) Trastuzumab-DM1: mechanisms of action and mechanisms of resistance [abstract 223]. Eur J Cancer 8(suppl):73

13. Krop IE, Beeram M, Modi S, Jones SF, Holden SN, Yu W, Girish S, Tibbitts J, Yi JH, Sliwkowski MX, Jacobson F, Lutzker SG, Burris HA (2010) Phase I study of trastuzumab-DM1, an HER2 antibody-drug conjugate, given every 3 weeks to patients with HER2-positive metastatic breast cancer. J Clin Oncol 28:26982704

14. Burris HA 3rd, Rugo HS, Vukelja SJ, Vogel CL, Borson RA, Limentani S, Tan-Chiu E, Krop IE, Michaelson RA, Girish S, Amler L, Zheng M, Chu YW, Klencke B, O'Shaughnessy JA (2011) Phase II study of the antibody drug conjugate trastuzumab-DM1 for the treatment of human epidermal growth factor receptor 2 (HER2)-positive breast cancer after prior HER2-directed therapy. J Clin Oncol 29:398-405

15. Krop I, LoRusso P, Miller KD, Modi S, Yardley D, Rodriguez G, Lu M, Burington B, Agresta S, Rugo H (2010) A phase 2 study of the HER2 antibody-drug conjugate trastuzumab-DM1 (T-DM1) in patients (pts) with HER2-positive metastatic breast cancer (MBC) previously treated with trastuzumab, lapatinib, and chemotherapy [abstract 277O]. Ann Oncol 21(suppl 8): viii97

16. Lewis-Phillips GD, Li G, Dugger DL, Crocker LM, Parsons KL, Mai E, Blättler WA, Lambert JM, Chari RV, Lutz RJ, Wong WL, Jacobson FS, Koeppen H, Schwall RH, Kenkare-Mitra SR, Spencer SD, Sliwkowski MX (2008) Targeting HER2-positive breast cancer with trastuzumab-DM1, an antibody-cytotoxic drug conjugate. Cancer Res 68:9280-9290

17. Chari RV, Martell BA, Gross JL, Cook SB, Shah SA, Blättler WA, McKenzie SJ, Goldmacher VS (1992) Immunoconjugates containing novel maytansinoids: promising anticancer drugs. Cancer Res 52:127-131

18. Lambert JM (2005) Drug-conjugated monoclonal antibodies for the treatment of cancer. Curr Opin Pharmacol 5:543-549

19. Wu AM, Senter PD (2005) Arming antibodies: prospects and challenges for immunoconjugates. Nat Biotechnol 23:1137-1146

20. Erickson HK, Park PU, Widdison WC, Kovtun YV, Garrett LM, Hoffman K, Lutz RJ, Goldmacher VS, Blättler WA (2006) Antibody-maytansinoid conjugates are activated in targeted cancer cells by lysosomal degradation and linker-dependent intracellular processing. Cancer Res 66:4426-4433

21. Gupta M, Wang B, Carrothers T, Joshi A, LoRusso PM, Chu W, Shih T, Loecke D, Girish S (2011) Exposure-response analysis in patients with HER2-positive (HER2+) metastatic breast cancer (MBC) to assess the effect of T-DM1 on QTc prolongation [abstract PII-64]. Clin Pharmacol Ther 89(suppl 1):S58

22. Gupta M, LoRusso PM, Wang B, Yi J-H, Burria HA, Beeram M, Modi S, Chu Y-W, Agresta S, Klenke B, Joshi A, Girish S (2011) Clinical implications of pathophysiological and demographic covariates on the population pharmacokinetics of trastuzumabDM1, a HER2-targeted antibody-drug conjugate, in patients with HER2-positive metastatic breast cancer. J Clin Pharm. doi:10.1177/ 0091270011403742

23. Bender BC, Schaedeli Stark F, Joshi A, Chu Y, Rugo HS, Krop IE, Girish S, Gupta M (2011) Semi-physiologic population pharmacokinetic/pharmacodynamic (PK/PD) model of thrombocytopenia 
characterizing the effect of trastuzumab-DM1 (T-DM1) on platelet counts in patients with HER2-positive MBC [abstract 605]. J Clin Oncol 29(15s):71

24. Burris HA 3rd, Lu D, Dees EC, Cortes J, Yi J-H, Shih T, Girish S (2010) Pharmacokinetic (PK) interaction potential of trastuzumabDM1 (T-DM1) and pertuzumab (P) in patients with HER2-positive, locally advanced or MBC: results from a phase $1 \mathrm{~b} / 2$ study [abstract P3-14-06]. Cancer Res 70(suppl 2):293s-294s

25. Lu D, Krop I, Modi S, Elias A, LoRusso P, Huang J, Lu M, Girish S (2010) Pharmacokinetics (PK) of trastuzumab-DM1 (T-DM1) and paclitaxel $(\mathrm{T})$ in patients with HER2-positive locally advanced or metastatic breast cancer (MBC) previously treated with a trastuzumab-containing regimen [abstract P3-14-22]. Cancer Res 70(suppl 2):300s

26. Gupta M, LoRusso P, Burris HA, Wang B, Joshi A, Tong YB, Chu Y, Girish S (2011) Pharmacokinetic and pathophysiological covariates influencing treatment outcomes with T-DM1 in patients with HER2-positive metastatic breast cancer [abstract 633]. J Clin Oncol 29:78s

27. Roskos LK, Davis CG, Schwab GM (2004) The clinical pharmacology of therapeutic monoclonal antibodies. Drug Dev Res 61:108-120

28. Lu D, Gupta M, Wang B, Joshi A, Theil F, Krop I, Burris H, Yi J, Girish S (2011) An integrated population pharmacokinetic model for a first-in-class HER2 targeted antibody-drug conjugate trastuzumab DM1 (T-DM1): simultaneous modeling of T-DM1 and total trastuzumab pharmacokinetics in heavily pretreated HER2+ metastatic breast cancer patients [abstract PII-51]. Clin Pharmacol Ther 89(suppl 1):S54

29. Shen B, Bumbaca D, Saad O, Yue Q, Pastuskovas C, Khojasteh C, Wang B, Tibbitts J, Kaur S, LoRusso P, Chu W, Girish S (2011) Metabolic fate and pharmacokinetic characterization of T-DM1: an emphasis on preclinical and clinical catabolism [abstract PIII72]. Clin Pharmacol Ther 89(suppl 1):S90 